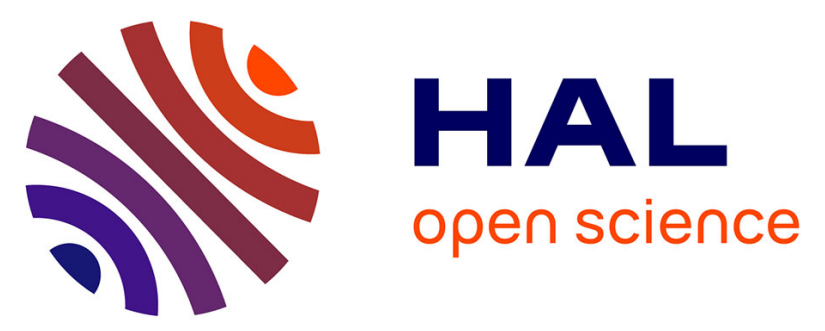

\title{
Influence of organophosphorous silica precursor on the thermal and fire behaviour of a PA66/PA6 copolymer
} Jihane Sahyoun, Véronique Bounor-Legare, Laurent Ferry, Rodolphe Sonnier, A. Bonhomme, Philippe Cassagnau

\section{- To cite this version:}

Jihane Sahyoun, Véronique Bounor-Legare, Laurent Ferry, Rodolphe Sonnier, A. Bonhomme, et al.. Influence of organophosphorous silica precursor on the thermal and fire behaviour of a PA66/PA6 copolymer. Polymer Degradation and Stability, 2015, 115, pp.117-128. 10.1016/j.polymdegradstab.2015.02.017 . hal-01154465

\author{
HAL Id: hal-01154465 \\ https://hal.science/hal-01154465
}

Submitted on 4 Jun 2021

HAL is a multi-disciplinary open access archive for the deposit and dissemination of scientific research documents, whether they are published or not. The documents may come from teaching and research institutions in France or abroad, or from public or private research centers.
L'archive ouverte pluridisciplinaire HAL, est destinée au dépôt et à la diffusion de documents scientifiques de niveau recherche, publiés ou non, émanant des établissements d'enseignement et de recherche français ou étrangers, des laboratoires publics ou privés. 


\title{
Influence of organophosphorous silica precursor on the thermal and fire behaviour of a PA66/PA6 copolymer
}

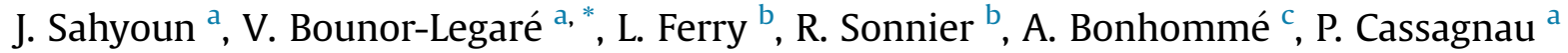 \\ ${ }^{a}$ Université de Lyon, Université de Lyon 1, CNRS, UMR5223, IMP@Lyon 1, 15 Boulevard Latarjet, F-69622 Villeurbanne, France \\ ${ }^{\mathrm{b}}$ Centre des Matériaux des Mines d'Alès (C2MA), École des Mines d'Alès, 6 Avenue de Clavières, F-30319 Alès, France \\ ${ }^{\mathrm{c}}$ Université de Lyon, Université de Lyon 1, Institut des Sciences Analytiques, UMR5280, CNRS, ENS-Lyon, 5 rue de la Doua, F-69100 Villeurbanne, France
}

\section{A B S T R A C T}

An organophosphorus silica filler was generated in situ the molten PA66 copolymer (Cop-PA) during extrusion process without adding solvents. Nanocomposites synthesis is based on hydrolysis-condensation reactions of diethylphosphatoethyltriethoxysilane precursor ( $\mathrm{SiP}$ ). The thermal stability of Cop-PA/ $\mathrm{SiP}$ nanocomposites and the major degradation products were studied by thermogravimetric analysis (TGA) and TGA coupled with Infrared spectrometry (TGA/FTIR). The Pyrolysis Combustion Flow Calorimeter (PCFC) and cone calorimeter were used to investigate the fire behaviour of the nanocomposites. Results showed a decrease by more than $50 \%$ of the peak of heat release rate (PHRR) and the formation of an expanded char layer with the addition of only $0.91 \mathrm{wt} \%$ of silicon and $0.96 \mathrm{wt} \%$ of phosphorus by this original route of fillers dispersion.

Keywords:

PA66 copolymers

Diethylphosphatoethyltriethoxysilane

Reactive extrusion

Sol-gel

In situ nanocomposites

Fire-retardancy

\section{Introduction}

The development of environmentally friendly flame retardants has become a major challenge in the modern polymer industry. The halogenated compounds have been proved to reduce hazard during polymer combustion and pyrolysis, but may present health and ecological issues [1]. Phosphorous flame retardants, which represented $20 \%$ of the flame retardant consumption in 2006 in Europe [2], are often proposed as alternatives for halogenated compounds. Polyamide 66 (PA66), as an engineering thermoplastic, is playing an important role in modern industry due to its high tensile strength, good chemical resistance, low friction coefficient and easy processing properties. However, PA66 has some disadvantages, such as high moisture absorptivity and easy flammability [3]. Therefore, PA66 needs to be flame retarded. In this paper, the most attention will be paid to the phosphorous flame-retardant additive approach. The range of phosphorous flame retardants is very broad, including organic and inorganic compounds: red phosphorus, organic and inorganic phosphates, phosphonates and phosphinates [4]. Phosphorous compounds are known to act in both, the condensed phase by creating a charred layer due to dehydration and further

\footnotetext{
* Corresponding author.
}

crosslinking reactions or in the gaseous phase by releasing radicals such as $\mathrm{PO}^{\circ}, \mathrm{PO}_{2}{ }^{\circ}$ and $\mathrm{HPO}^{\circ}$ which scavenge free radicals $\mathrm{OH}^{\circ}$ and $\mathrm{H}^{\circ}$ responsible for the spread of the flame [5-7]. The activity of phosphorus depends on the nature of the used flame retardant, the chemical structure of the matrix as well as the interaction with other additives.

A typical example is glass- (GF) reinforced PA66 containing $6-8$ wt\% of red phosphorus, which achieves $\mathrm{V}-0$ classification in the UL 94 test [8]. The thermal and thermo-oxidative decomposition of reinforced PA66 containing red phosphorus in comparison to PA66/ $\mathrm{GF}$, is characterized by at least three different steps, which strongly overlap for PA66/GF and are clearly separated for PA66/GF/red P [9]. The cone calorimeter test showed that PA66/GF/red $P$ is an effective charring material, resulting in a clear reduction in Total Heat Evolved (THE) and HRR values, and achieving V-0 classification in the UL 94, thus a mainly solid-phase mechanism was reported.

An intumescent coating is observed with the addition of ammonium polyphosphate (APP) to the PA66 [10]. APP decreases the onset degradation temperature of the polyamide and creates a protective layer made of polyphosphoric acids, thermally stable on the surface of the material, which can be expanded to a cellular structure by gaseous degradation products. This reactivity is also established for polyamide 6 [11]. For PA66, the effect was most evident in terms of oxygen index which increased with APP 
concentration in the composites (10, 20, 30 and 40wt\%). The addition of $25 \mathrm{wt} \%$ of melamine polyphosphate (MPP) to a glass fibre reinforced PA66 [12] leads to a V-0 classification. MPP system acts as a char-forming (intumescent) flame retardant in both PA66 and PA6 [13]. It releases phosphorus based acids, which accelerate the decomposition reaction and the crosslinking of PA66. Meanwhile, the nitrogen compounds released contribute to the expansion of the molten phase, the formation of the intumescent layer as well as the dilution of the fuel gas $[12,13]$.

Another phosphorus compound, aluminium tris(diethylphosphinate) also referred as AlPi, is one of the most used phosphinates in glass-fibre reinforced polyamides [14]. AlPi is usually used in the presence of melamine polyphosphate [15] or melamine cyanurate (20wt\% of FR) [16,17]. The effect of the addition of AlPi with MPP and zinc borate (18wt\% of FR) in PA66 containing 30wt\% of glass fibre was also studied [18]. In fact, AlPi acts as a flame inhibitor in the gas phase, while MPP leads to a fuel dilution and a phosphate barrier formation. The addition of AlPi to MPP results in an aluminium phosphate barrier formation while the fuel dilution effect became less effective. Combining, AlPi, MPP and zinc borate shows a much more improved barrier effect with the formation of a boron-aluminium phosphate layer. In a recent study [19] based on the combination of AlPi, zinc borate and melamine salts (Safire ${ }^{\circledR}$ ) in a glass reinforced (30wt\%) PA66, it was found that all formulations containing 15,18 and $20 \mathrm{wt} \%$ of flame retardants have been classified V-0 in the UL 94 test. These composites also pass the glow wire test at $960{ }^{\circ} \mathrm{C}$ and finally a significant decrease in HRR values was also observed in cone calorimeter test.

These flame retardants are usually added in the polymer matrix as preformed fillers. Few years ago, a new approach was developed as an alternative to this path of dispersion [20-22] and lately for improving the flame retardancy of thermoplastic polymers such as PA6 [23]. The syntheses are based on hydrolysis-condensation reactions of alkoxysilanes precursors during extrusion process without adding solvents. Besides creating the inorganic phase in polymer matrix, this strategy also offers an innovative way for tailoring material properties with the use of functionalized alkoxysilane precursor such as silicophosphorylated ones.

Theil-Van Nieuwenhuyse et al. [23] showed that in situ generation of phosphorylated silica by sol-gel method within a PA6 matrix in the molten state during extrusion is a very novel route for obtaining flame retarded nanocomposites. Results have shown a significant decrease about $50 \%$ of the heat of release rate and the formation of an important residue during cone calorimeter test with the addition of only $2.51 \mathrm{wt} \%$ of silicon and $2.46 \mathrm{wt} \%$ of phosphorus.

The aim of the present work was to develop this synthetic route, using the same precursor (diethylphosphatoethyltriethoxysilane) for enhancing the fire performance of a PA66/PA6 copolymer matrix using different loadings. More specifically, we focused on the degradation mechanisms of the nanocomposites as well as the mode of action of the in situ generated silicophosphorylated filler was deduced. Fire performance was based on cone calorimeter and pyrolysis combustion flow calorimeter tests.

\section{Experimental}

\subsection{Materials/preparation of compounds}

PA66/PA6 (90:10 wt\%) copolymer used in this study was kindly provided by Solvay group under the trade name STABAMID 25 RS 5 S2 and will be denoted Cop-PA. The organophosphorous alkoxysilane precursor (Diethylphosphatoethyltriethoxysilane, 92\%) denoted as SiP was purchased from ABCR Gelest (Germany).

Cop-PA pellets were dried $48 \mathrm{~h}$ at $80{ }^{\circ} \mathrm{C}$ under vacuum prior to use. The nanocomposites were prepared by melt blending in a corotating twin screw extruder (Leistriz LSM model, diameter $30 \mathrm{~mm}, \mathrm{~L} / \mathrm{D} 34$ ) at $250{ }^{\circ} \mathrm{C}$. The organophosphorous inorganic precursor was added into the matrix in the molten state at a constant flow rate using an external liquid pump. The special design of the screw, the processing temperature and the screw speed were adapted to the experiment in a manner to prevent the degradation of the matrix and to allow a continuous injection. Viscosimetry was performed to check if the hydrolysis-condensation reactions impact the copolymer molar mass. Values of average viscosimetric molar mass $\left(M_{\mathrm{v}}\right)$ were calculated from the intrinsic viscosity in aqueous $\mathrm{HCOOH}$ (90 vol\%) at $25^{\circ} \mathrm{C}$ by applying the Mark-Houwink equation with $K=0.061 \mathrm{~mL} / \mathrm{g}$ and $a=0.71$ [24]. Results (not shown here) have evidenced that the extrusion conditions and the introduction of alkoxysilane precursor during the process did not modify the molecular characteristics of Cop-PA.

A summary of the prepared nanocomposites is shown in Table 1.

In order to make an accurate study in TGA coupled infrared spectroscopy, a gel of the inorganic precursor (Diethylphosphatoethyltriethoxysilane) was prepared. In greater detail, $1.10 \mathrm{~g}$ of SiP were hydrolyzed with $3.3 \mathrm{~mL}$ of $\mathrm{HCl}(0.1 \mathrm{M})$ and $8.7 \mathrm{~mL}$ of distilled water [25]. The solution was stirred for $24 \mathrm{~h}$ at $80^{\circ} \mathrm{C}$, under nitrogen flow. In order to eliminate any trace of solvent the solution was exposed to air. Once gelled, the sample was air dried for 4 days and then dried at $80{ }^{\circ} \mathrm{C}$ in an oven for around $14 \mathrm{~h}$.

\subsection{Characterization of thermal decomposition}

\subsubsection{Thermogravimetric analysis (TGA)}

Thermogravimetric experiments were performed using an SDT Q600 TGA from TA Instruments. The samples were heated in open alumina pans from room temperature up to about $750{ }^{\circ} \mathrm{C}$ at a heating rate of $10{ }^{\circ} \mathrm{C} / \mathrm{min}$ under nitrogen or synthetic air flow of $25 \mathrm{~mL} / \mathrm{min}$. Reported data are $T_{\text {onset }}$ at which the formulation displays $5 \mathrm{wt} \%$ weight loss, $T_{\mathrm{m}}$ at which the decomposition rate is the highest and the amount of residue at $700{ }^{\circ} \mathrm{C}$.

\subsubsection{TGA coupled gas chromatography and mass spectroscopy (TGA-GC/MS)}

Measurements were carried out on an SDT Q600 TGA coupled with a 6890N GC system/5973N MS detector from Agilent Instruments. For this purpose, a gas storage interface IST16 developed by SRA Instruments was connected to the thermogravimetric balance and the GC network throughout two heated transfer lines, thus allowing us to retrieve and isolate gas fractions from thermal analysis. These fractions are then injected into the GC/MS system. The GC column, HP-5MS $(20 \mathrm{~m} \times 0.18 \mathrm{~mm} \times 0.18 \mu \mathrm{m})$, was held at $60{ }^{\circ} \mathrm{C}$, and then heated up to $280^{\circ} \mathrm{C}$ at a heating rate of $40^{\circ} \mathrm{C} / \mathrm{min}$. The inlet and the detector temperatures were maintained at $280^{\circ} \mathrm{C}$. MS spectra were obtained as a function of elution time with a mass range of $10-700 \mathrm{amu}$.

\subsubsection{TGA coupled with Fourier transform infrared spectroscopy (TGA-FTIR)}

In order to identify evolved decomposition products a Q50 thermogravimetric analyzer (TA Instruments) was coupled to a

Table 1

Composition of the materials prepared through the extrusion process.

\begin{tabular}{lllll}
\hline Materials & $\begin{array}{l}\text { Measured SiP } \\
\text { content (wt\%) }\end{array}$ & $\begin{array}{l}\text { Measured } \\
\text { wt\% of } \mathrm{Si}^{\mathrm{a}}\end{array}$ & $\begin{array}{l}\text { Measured } \\
\text { wt\% of } \mathrm{P}^{\mathrm{a}}\end{array}$ & Ratio P/Si \\
\hline Cop-PA & - & - & - & - \\
C8SiP & 8 & 0.72 & 0.74 & 1.03 \\
C11SiP & 11 & 0.91 & 0.96 & 1.05 \\
C13SiP & 13 & 1.14 & 1.25 & 1.09 \\
\hline
\end{tabular}

a Determined by elemental analysis. 
Nicolet Nexus spectrometer with an MCT detector. The temperatures of the transfer line and the gas cell were maintained at $240^{\circ} \mathrm{C}$. The infrared spectrometer was operated at an optical resolution of $4 \mathrm{~cm}^{-1}$. Experiments were performed under nitrogen or air with a gas flow rate of $90 \mathrm{~mL} / \mathrm{min}$. The samples (about $10 \mathrm{mg}$ ) were heated in open alumina pans, from $30^{\circ} \mathrm{C}$ up to about $700{ }^{\circ} \mathrm{C}$ at a heating rate of $5{ }^{\circ} \mathrm{C} / \mathrm{min}$. Components identification was based on characteristic peaks and by subtraction of recognizable products (such as water, ...), evolution profiles were also plotted in terms of time or temperature.

\subsubsection{Pyrolysis-combustion flow calorimeter (PCFC)}

Pyrolysis combustion flow calorimeter (PCFC) analyses were performed on a Fire Testing Technology (FTT) apparatus. Samples around $2-3 \mathrm{mg}$ were heated from $85^{\circ} \mathrm{C}$ up to $750{ }^{\circ} \mathrm{C}$ at a heating rate of $1{ }^{\circ} \mathrm{C} / \mathrm{s}$ under nitrogen flow. The degradation products are then collected in a second chamber (combustor) maintained at $900{ }^{\circ} \mathrm{C}$ in the presence of oxygen $\left(\mathrm{N}_{2} / \mathrm{O}_{2}\right.$ mixture $\left.80 / 20\right)$. In these conditions, the complete combustion of the pyrolysis gases takes place. The HRR value is calculated from oxygen consumption according to the principle of Huggett [26], which explains that for organic compounds, the heat of combustion is proportional to the amount of oxygen required for combustion; i.e. $13.1 \mathrm{~kJ} / \mathrm{g}$ of oxygen consumed. In this work, we focus only on the total heat release (THR) which corresponds to the area under the heat release rate curve. The uncertainties in THR for the apparatus are about $5 \%$.

The ratio between the total heat release and the mass loss (measured in thermogravimetric analysis) allows calculating the effective heat of complete combustion (called EHC $_{\text {PCFC }}$ ). Combustion efficiency in cone calorimeter is then calculated as the ratio between the $\mathrm{EHC}$ in cone calorimeter $\left(\mathrm{EHC}_{\text {cone }}\right)$ and $\mathrm{EHC}_{\mathrm{PCFC}}$.

\subsection{Characterization of fire behaviour}

\subsubsection{Cone calorimeter (CC)}

The cone calorimeter is the most suitable apparatus to simulate a fire scenario at bench scale. Therefore, the combustion behaviour of materials was investigated using a cone calorimeter (CC) supplied by FTT company. Experiments were carried out at an irradiance of $50 \mathrm{~kW} / \mathrm{m}^{2}$ according to ISO 5660 standard. The distance between the cone heater and the sample $\left(100 \times 100 \times 4 \mathrm{~mm}^{3}\right)$ was $25 \mathrm{~mm}$. Time to ignition (TTI, s), Time to flame out (TTF, s), Total Heat Release (THR, $\mathrm{kW} / \mathrm{m}^{2}$ ), Heat Release Rate (HRR, $\mathrm{kW} /$ $\mathrm{m}^{2}$ ), and peak of heat release rate (PHRR, $\mathrm{kW} / \mathrm{m}^{2}$ ) were measured. The value of HRR is also calculated from the oxygen consumption according to the principle of Huggett [26]. To ensure significant and reproducible data, experiments were repeated several times. The uncertainties in measurements for the apparatus are about $15 \%$.

\subsubsection{CC coupled Fourier transform infrared spectroscopy}

During each experiment, the main gaseous species emissions from the combustion of the materials were continuously and simultaneously recorded. The Gram-Schmidt is the infrared chromatogram of the gases from the compound which has undergone the temperature rise. For this purpose, the cone calorimeter apparatus was coupled to an Antaris IGS analyser with an MCT detector (recommended for its high performance) from Thermo Scientific Company. Optical resolution for exhaust gas measurements was set at $0.5 \mathrm{~cm}^{-1}$ to avoid interference problems potentially caused by water's absorbance bands at lower resolutions. Both the IR spectrometer and the transfer line are heated to $160{ }^{\circ} \mathrm{C}$ to minimize condensation of high boiling point effluents.

\subsubsection{Residues morphology}

The morphological study of the residual layer formed during sample combustion in cone calorimeter test was performed using a scanning electron microscope FEI Quanta 200 SEM equipped with an energy dispersive X-ray (EDX) spectrometer. Images were obtained under high vacuum at a voltage of $12.5 \mathrm{kV}$. For sample preparation, the residue was stuck to a sample holder with a thin silver layer.

\subsection{Elemental analysis}

Elemental analysis was conducted at the Service Central d'Analyse (SCA, CNRS, 5 Rue de la Doua, F-69100, Villeurbanne, France). Silicon and Phosphorus contents were determined by ICP-AES (inductively coupled plasma-atomic emission spectrometer). Carbon content was determined by either catharometry or specific infrared detectors and Nitrogen content by catharometry.

\section{Results and discussion}

\subsection{Thermal decomposition}

\subsubsection{Thermal stability and residue}

3.1.1.1. Thermal degradation of Cop-PA. The TG curves for the pure copolymer measured under helium and air flow are shown in Fig. 1. A minor weight loss ( $<1 \mathrm{wt} \%)$ is observed between 100 and $200{ }^{\circ} \mathrm{C}$ corresponding to the residual water in the samples. Under inert atmosphere, one major degradation event was present with an onset decomposition temperature of $394{ }^{\circ} \mathrm{C}$ yielding an overall mass loss of $98 \mathrm{wt} \%$. Under synthetic air flow, Cop-PA undergoes two main degradation steps. The first important degradation step occurs between 350 and $480{ }^{\circ} \mathrm{C}$ and a second one appears between 480 and $600{ }^{\circ} \mathrm{C}$. This thermal degradation behaviour of polyamides, under air, was described in the literature [27] by the formation of a carbonaceous layer that remains stable until $500{ }^{\circ} \mathrm{C}$ and then oxidizes to volatiles at higher temperatures.

3.1.1.2. Thermal degradation of Cop/SiP nanocomposites. TG and DTG curves of Cop-PA and Cop/SiP nanocomposites under helium are shown in Fig. 2. All the nanocomposites exhibit lower decomposition temperatures and higher amount of residues than the neat Cop-PA. More precisely, $T_{\text {onset }}$ decreases with the amount

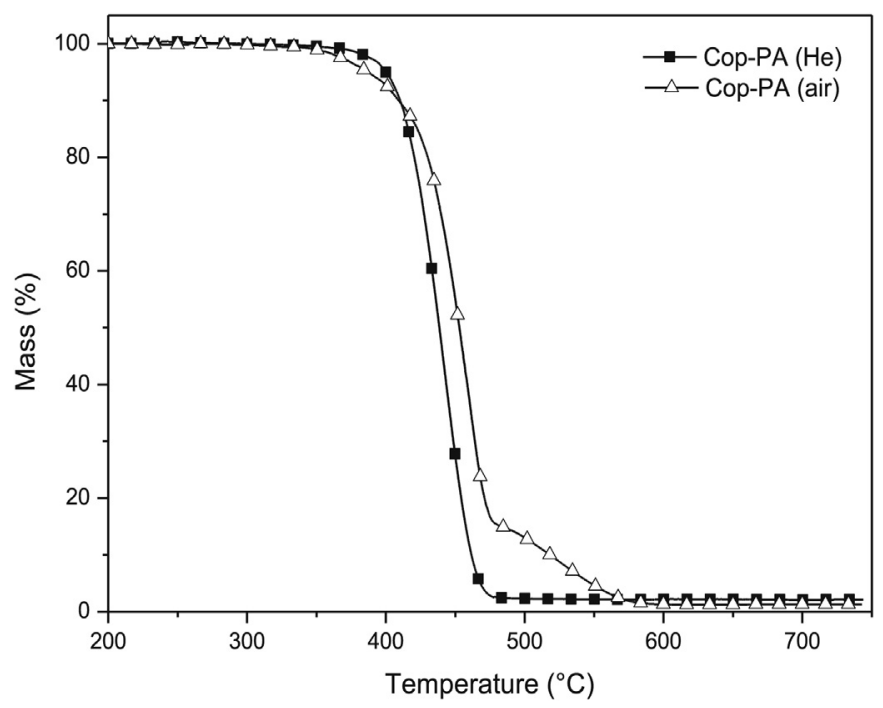

Fig. 1. TG curves of Cop-PA under helium and air (heating rate $=10^{\circ} \mathrm{C} / \mathrm{min}$ ). 


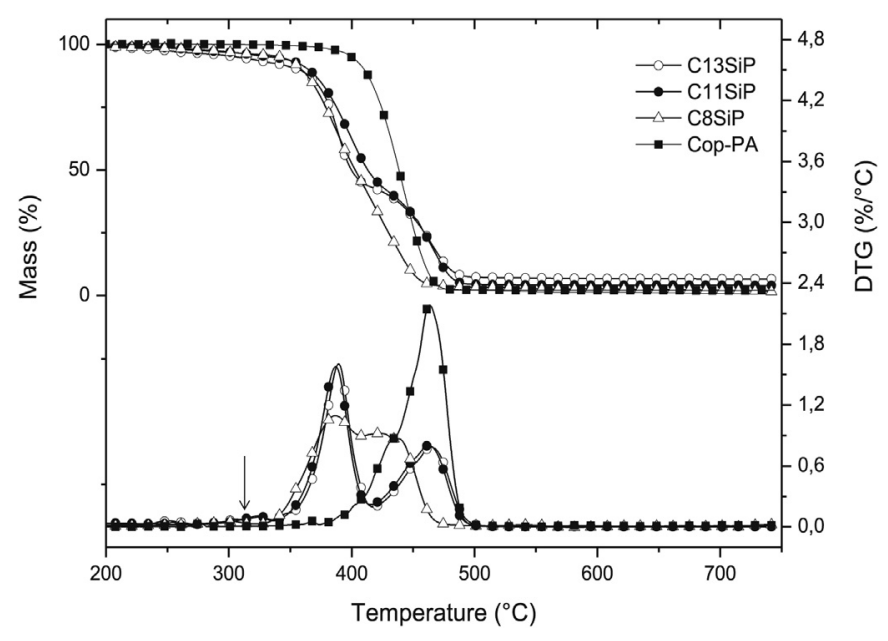

Fig. 2. TG and DTG curves of Cop-PA and Cop/SiP nanocomposites under helium (heating rate $10{ }^{\circ} \mathrm{C} / \mathrm{min}$ ).

of SiP introduced (Table 2). A minor mass loss is also observed between 100 and $200{ }^{\circ} \mathrm{C}$ corresponding to the residual water and ethanol (as evidenced in Section 3.1.2) released due to hydrolysis-condensation reactions (ethanol probably trapped on the surface of the material). Furthermore, the thermal degradation of all Cop/SiP samples consists of two main degradation steps whose maximum rates are between $375{ }^{\circ} \mathrm{C}$ and $460{ }^{\circ} \mathrm{C}$. The main difference observed concerns the first step of degradation, which takes place at temperatures lower than for the Cop-PA. In fact, the weight loss temperature in the first step decreases with increasing SiP content, while the position of the maximum rate of the second step is slightly shifted from $428{ }^{\circ} \mathrm{C}$ to about $460{ }^{\circ} \mathrm{C}$. The decrease of the initial degradation temperature is consistent with the observations reported in the literature explaining that the phosphorus based flame retardants can accelerate the thermal decomposition of the polyamide matrix. For example, the DTG curves of PA66/Red Phosphorus materials had shown a second degradation step following the main one. The onset temperature of decomposition was also decreased by about $40{ }^{\circ} \mathrm{C}$, whereas the end-set temperature was increased about $15^{\circ} \mathrm{C}$ [9]. Such behaviour was also found in PA66/APP (ammonium polyphosphate) systems. DTG curves had shown that these materials exhibit a two-step process of degradation. The position of the maximum rate of weight loss in the first step of degradation was about 85-95 ${ }^{\circ} \mathrm{C}$ lower than the position of the single maximum for the thermal decomposition of pure PA66 [10]. The composite containing $8 \mathrm{wt} \%$ of SiP presents a shoulder rather than a peak; this is probably due to the lower concentration of SiP compared with other compounds.

The origin of the small mass loss observed around $315{ }^{\circ} \mathrm{C}$ will be discussed later. TGA and DTG curves under air for mixtures containing SiP will be discussed later in the section referring to TGA coupled IR.

Table 2

Thermogravimetric analysis results under helium.

\begin{tabular}{llll}
\hline Sample & $T_{\text {Onset }}\left({ }^{\circ} \mathrm{C}\right)$ & $T_{\mathrm{m}}\left({ }^{\circ} \mathrm{C}\right)$ & Residue (wt\%) \\
\hline Cop-PA & 394 & 440 & 2 \\
Cop-8SiP & 353 & $389-428^{\mathrm{a}}$ & 2.8 \\
Cop-11SiP & 332 & $387-458^{\mathrm{b}}$ & 4.2 \\
Cop-13SiP & 281 & $375-460^{\mathrm{b}}$ & 6.1 \\
\hline a Shoulder. & & & \\
b Second peak. & & &
\end{tabular}

\subsubsection{Evolved gas analysis and decomposition mechanisms}

The major degradation products and the various decomposition steps were studied under both inert and oxidative atmospheres, thus allowing us to separate the spectra of different effluents and to plot their evolution profile as a function of time or temperature.

3.1.2.1. TGA-GC/MS results. In order to identify the major degradation products, extracted ion chromatograms collected at different $\mathrm{m} / \mathrm{z}$ did not reveal the presence of caprolactam as a major degradation product of PA6, thus allowing us to consider that the low mass contribution of PA6 (10wt\%) does not significantly influence the degradation of the copolymer matrix.

Under inert atmosphere, the gases detected consist mainly of water vapour, ammonia, carbon dioxide, hydrocarbons, amines and cyclopentanone. The formation of cyclopentanone and its derivatives as major degradation products for PA 66 were discussed in the literature [28-30] and several possible mechanisms of cyclopentanone formation were also suggested [30].

Taking into consideration the time of gas storage and injection, we managed to plot the evolution of cyclopentanone throughout the test. The spectral signature of this gas was detected between 360 and $500{ }^{\circ} \mathrm{C}$ under inert atmosphere but not under air, leading us to consider that, under air, cyclopentanone probably undergoes several decompositions into products of lower molar mass.

With the addition of SiP, except the presence of ethanol as a byproduct of the hydrolysis-condensation reactions, the analysis revealed the emission of the same gases but not necessarily at the same temperatures and in the same proportions for the nanocomposites as for the copolymer. The evolution of cyclopentanone as a function of time for Cop-PA and C11SiP under helium is shown in Fig. 3.

\subsubsection{TGA-FTIR results}

3.1.2.2.1. Products in relation with Cop-PA composition. As discussed in Section 3.1.1, under inert atmosphere, the Cop-PA displays one mass loss between 350 and $480{ }^{\circ} \mathrm{C}$. In this range of temperature, infrared analysis shows the emission of the following gases: carbon dioxide $\left(\mathrm{CO}_{2}\right)$, ammonia $\left(\mathrm{NH}_{3}\right)$, water vapour, hydrocarbons, as well as various carbonyl compounds. From 440 up to $500{ }^{\circ} \mathrm{C}$, a band at $1666 \mathrm{~cm}^{-1}$ assigned to an amide carbonyl is observed. Another carbonyl vibration at $1766 \mathrm{~cm}^{-1}$ related to a cyclic ketone appears between 350 and $465{ }^{\circ} \mathrm{C}$. It was attributed to

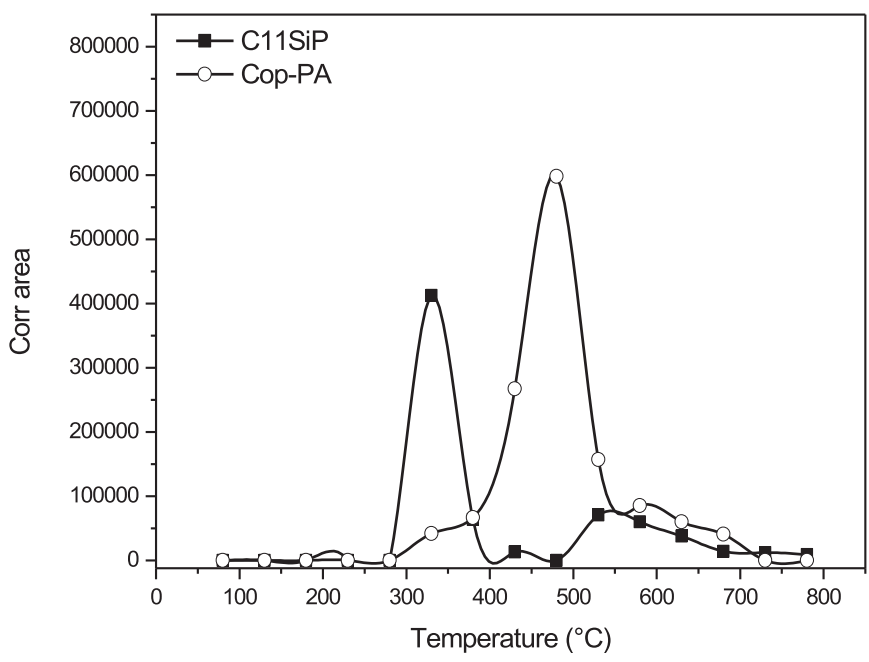

Fig. 3. Spectral signature of cyclopentanone under helium for Cop-PA and C11SiP 
cyclopentanone [18,29]. Finally, another carbonyl band located at $1702 \mathrm{~cm}^{-1}$ is observed between 395 and $480^{\circ} \mathrm{C}$ also assigned to an amide carbonyl. Methane $\left(\mathrm{CH}_{4}\right)$ was also released around $480{ }^{\circ} \mathrm{C}$.

The thermogram recorded for Cop-PA under air showed two mass losses. The first mass loss occurs from 300 to $470{ }^{\circ} \mathrm{C}$, followed by the second one from 470 to $700{ }^{\circ} \mathrm{C}$. Analysis showed the emission of the same gases found under inert atmosphere, except for carbon monoxide, isocyanic acid (HNCO), hydrogen cyanide ( $\mathrm{HCN})$ and some aliphatic ketones with maximum emission intensity around 440 and $455^{\circ} \mathrm{C}$. Aldehydes like acetaldehyde appear between 380 and $470{ }^{\circ} \mathrm{C}$. From $490^{\circ} \mathrm{C}$, unassigned carbonyl functions were also observed.

3.1.2.2.2. Decomposition products of SiP-based nanocomposites. Under inert atmosphere, the TGA curve of C13SiP (Fig. 4) shows four mass losses. The first one about $5.5 \mathrm{wt} \%$ takes place between room temperature and $270{ }^{\circ} \mathrm{C}$, followed by a minor mass loss of $3 \mathrm{wt} \%$ between 270 and $320^{\circ} \mathrm{C}$. A significant weight loss about $46.2 \mathrm{wt} \%$ occurs in a range of temperature between 320 and $420{ }^{\circ} \mathrm{C}$ and the latter is of $39.3 \mathrm{wt} \%$ between 400 and $700{ }^{\circ} \mathrm{C}$, with a final residue of $6 w t \%$ at $700{ }^{\circ} \mathrm{C}$.

Infrared analysis showed the emission of various volatile products. The evolution profile of each detected gas was plotted as a function of time (Fig. 5). This led us to determine the nature of the gases emitted during the various weight losses. Water vapour was found between 115 and $220^{\circ} \mathrm{C}$ corresponding to the residual water in the sample. Another amount of water was also detected between 330 and $400{ }^{\circ} \mathrm{C}$ with maximum emission intensity at $375{ }^{\circ} \mathrm{C}$, regarded as a volatile of the polyamide degradation or polycondensation of some silanols. Ethanol was also identified in a range of temperature between 95 and $325^{\circ} \mathrm{C}$, with a maximum intensity at $315^{\circ} \mathrm{C}$. As we discussed earlier, ethanol trapped on the surface of the sample is released around $100{ }^{\circ} \mathrm{C}$. At higher temperatures the amount released is likely due to ethanol trapped in the core of the sample. It is also to be mentioned that ethanol yielded between 280 and $325{ }^{\circ} \mathrm{C}$ is probably due to a new amount of ethanol produced during further hydrolysis-condensation reaction of unreacted SiP, or further condensation reaction of some silanols with alkoxysilane groups. Results revealed also the presence of ethylene $\left(\mathrm{C}_{2} \mathrm{H}_{4}\right)$ between 270 and $700{ }^{\circ} \mathrm{C}$ with a maximum intensity around $315^{\circ} \mathrm{C}$, its formation will be discussed later. It was also found that the major volatiles were carbon dioxide between 290 and $430{ }^{\circ} \mathrm{C}$, and ammonia between 315 and $495{ }^{\circ} \mathrm{C}$. The maximum emission intensity for both gases was around $375{ }^{\circ} \mathrm{C}$. Furthermore, the analysis showed the presence of methane

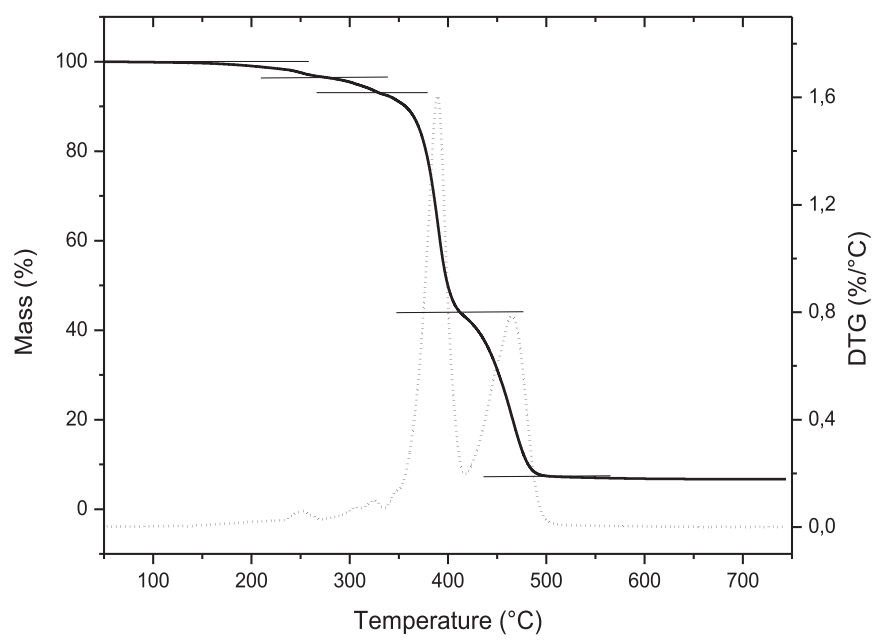

Fig. 4. TG and DTG curves of $\mathrm{C} 13 \mathrm{SiP}$ under nitrogen (heating rate $5^{\circ} \mathrm{C} / \mathrm{min}$, flow rate $90 \mathrm{~mL} / \mathrm{min})$. between 410 and $650{ }^{\circ} \mathrm{C}$ and also aliphatic hydrocarbons from $325{ }^{\circ} \mathrm{C}$ till the end of the test. A carbonyl vibration around $1705 \mathrm{~cm}^{-1}$ was observed in a range of temperature between 320 and $460{ }^{\circ} \mathrm{C}$, corresponding probably to an amide or an aliphatic ketone. Few vibration bands between 285 and $315^{\circ} \mathrm{C}$ may indicate the presence of phosphorous compounds.

The TGA thermogram recorded for C13SiP under air showed five mass losses (Fig. 6). In similarity to the sample under nitrogen, two mass losses are observed from room temperature to $320^{\circ} \mathrm{C}$, followed by two significant weight losses of $40 \mathrm{wt} \%$ between 315 and $400{ }^{\circ} \mathrm{C}$ and $33 \mathrm{wt} \%$ between 400 and $470{ }^{\circ} \mathrm{C}$. The final mass loss from $400{ }^{\circ} \mathrm{C}$ till the end of the test was about $14 \mathrm{wt} \%$ yielding a final residue of $4.8 \mathrm{wt} \%$.

Except for carbon monoxide, isocyanic acid and hydrogen cyanide released in a range of temperature between 375 up to about $650{ }^{\circ} \mathrm{C}$ with maximum emission intensities around $520{ }^{\circ} \mathrm{C}$, the analysis under air revealed the emission of the same gases found under inert atmosphere (Fig. 7). Some differences were observed in the maximum emission intensities for some gases; for example, two maxima were detected for water vapour and hydrocarbons around 375 and $515{ }^{\circ} \mathrm{C}$. In similarity, carbon dioxide released from $290{ }^{\circ} \mathrm{C}$ till the end of the test, had two emission maxima at 375 and $515^{\circ} \mathrm{C}$. Between 285 and $375^{\circ} \mathrm{C}$, a carbonyl vibration at $1759 \mathrm{~cm}^{-1}$ was observed; this band is consistent with cyclic ketone compounds such as cyclopentanone. In comparison with the analysis under inert atmosphere, few bands were detected between 280 and $314{ }^{\circ} \mathrm{C}$, indicating the presence of phosphorus compounds.

\subsection{Fire behaviour}

\subsubsection{Cone calorimeter data}

To complete the thermal properties, the fire behaviour of materials containing SiP was studied using a cone calorimeter with an incident heat flux of $50 \mathrm{~kW} / \mathrm{m}^{2}$. Heat release rate curves as a function of time for all materials are presented in Fig. 8 and main results are summarized in Table 3.

The ignition of SiP-based nanocomposites takes place earlier than the neat polymer. It was also noted that the peak of heat release rate (PHRR) decreased for all nanocomposites containing SiP. The minimum peak of heat release rate was observed when $11 \mathrm{wt} \%$ of SiP was added, corresponding to $0.91 \mathrm{wt} \%$ of silicon and $0.96 \mathrm{wt} \%$ of phosphorus. The same tendency is observed while adding $13 \mathrm{wt} \%$ of SiP with a decrease of the PHRR down to $410 \mathrm{~kW} /$ $\mathrm{m}^{2}$. A slight decrease in the effective heat of combustion (EHC) was also observed when SiP was incorporated into the Cop-PA.

Finally, the quantity of residue was increased with the addition of SiP, resulting in a decrease of total heat release (THR) values comparing to the neat polymer, due to higher residue yield.

Each of these parameters will be discussed in details later in the following sections.

\subsubsection{Analysis of the gases responsible for the ignition}

3.2.2.1. Cone calorimeter/FTIR. In order to identify the gases responsible for the ignition of the material, the cone calorimeter was coupled to an infrared spectrometer. The test was conducted at lower heat flux $\left(20 \mathrm{~kW} / \mathrm{m}^{2}\right)$ in a way to delay the ignition as much as possible and detect almost all of the released gases. The main quantified volatiles for Cop-PA and C11SiP were: nitrogen oxide $\left(\mathrm{NO}_{\mathrm{X}}\right), \mathrm{HCN}, \mathrm{NH}_{3}, \mathrm{H}_{2} \mathrm{O}$, methane, some hydrocarbons, $\mathrm{CO}$ and $\mathrm{CO}_{2}$. On the other hand, before the ignition of the C11SiP (around $4 \mathrm{~min}$ ) a significant amount of ethylene (ethene) with the presence of alcohol (ethanol) was observed (Fig. 9). Both gases can promote the ignition, however ethylene is a highly flammable gas with a net heat of combustion of $44.6 \mathrm{~kJ} / \mathrm{g}$ [31]. The origin of the early emission of ethylene may probably come from the phosphorous 


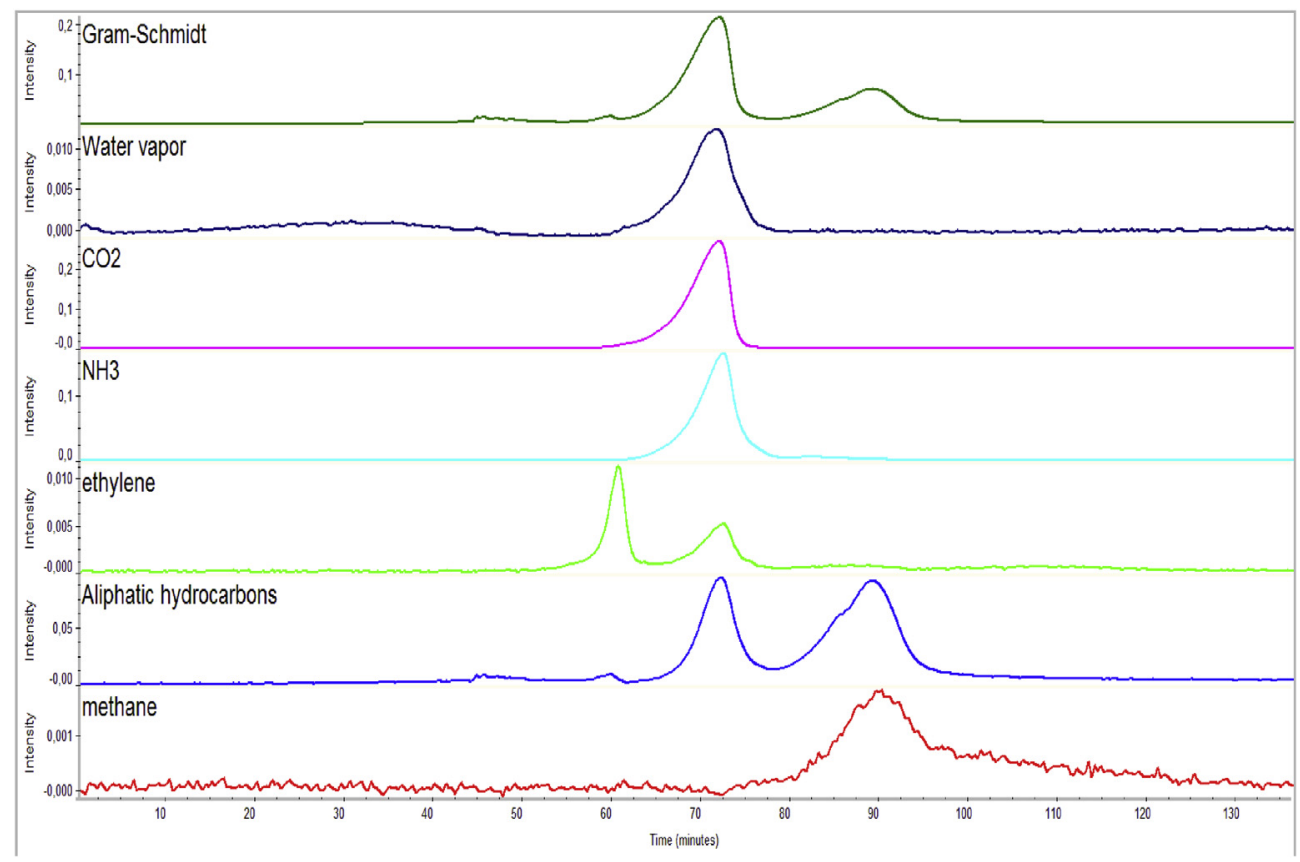

Fig. 5. Gram-Schmidt and chemigrams of C13SiP under nitrogen.

compound, or may be obtained by dehydration of ethanol at high temperatures.

In order to monitor this gas emission over the time, the gel of the hydrolyzed-condensed precursor (SiP) was analyzed with the TGA coupled FTIR by comparing it to the C13SiP composite, taking into consideration the release of ethanol, ethylene and any volatile compound detected before the degradation of the matrix. Ethanol was detected between 150 and $290{ }^{\circ} \mathrm{C}$ with maximum emission intensity around $230{ }^{\circ} \mathrm{C}$. Simultaneously, the appearance of bands characteristic of diethylether and ethylene was observed between 215 and $300{ }^{\circ} \mathrm{C}$. This proves that the reactions of dehydration and/or condensation of ethanol occur at elevated temperatures and probably phosphorus acts as an acid catalyst. Moreover, ethylene seems to be present in two stages: mainly with maximum emission intensity around $285^{\circ} \mathrm{C}$, then between 440 and $495{ }^{\circ} \mathrm{C}$. The release of ethylene at very high

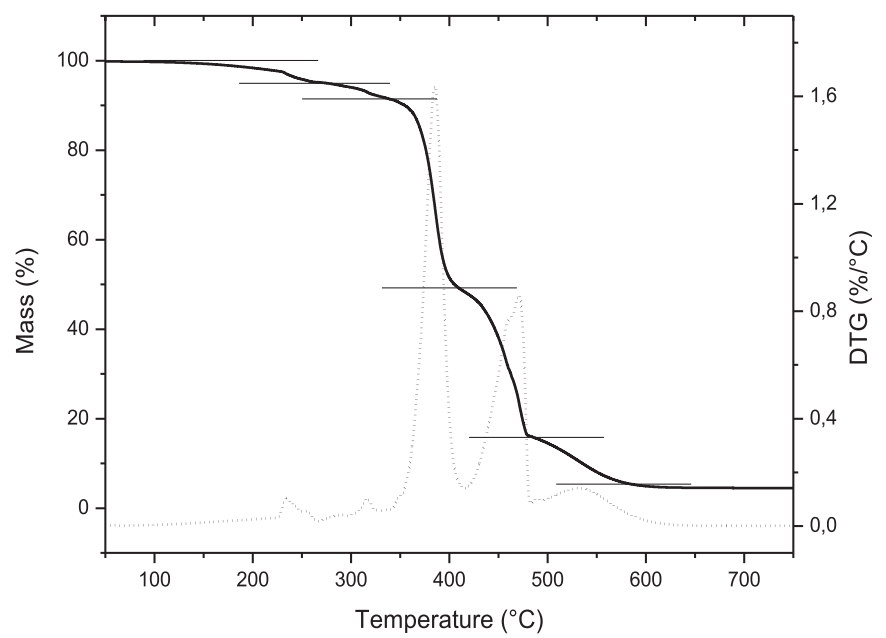

Fig. 6. TG and DTG curves of $\mathrm{C} 13 \mathrm{SiP}$ under air (heating rate $5{ }^{\circ} \mathrm{C} / \mathrm{min}$, flow rate $90 \mathrm{~mL} /$ $\min )$. temperatures (around $400{ }^{\circ} \mathrm{C}$ ) has been described several times in the literature about the decomposition of aluminium diethyl phosphinate (AlPi) [15,16,18]. In fact, AlPi decomposes into diethylphosphinic acid that decomposes releasing ethylene at temperatures between 467 and $527{ }^{\circ} \mathrm{C}$ [15]. As discussed before, the ethylene released before the matrix decomposition can also be due to the phosphorous compound. As a matter of fact, the formation of ethylene around $300{ }^{\circ} \mathrm{C}$ was described in the literature. The first suggested mechanism is the McLafferty rearrangement [32,33] (Fig. 10).

In another work, Gaan and Sun proposed two others mechanisms [34] based on Cope elimination and/or reverse Michael addition. They explained that such reactions could occur in case of phosphonate structure like N-hydroxymethyl-3dimethylphosphonopropionamid (HDPP) because of the polar nature of $\mathrm{P}=\mathrm{O}$ bond and availability of $\beta$-hydrogen.

On the other hand, FTIR spectra of $\mathrm{C} 11 \mathrm{SiP}$ revealed the presence of the following bonds vibrations: $\mathrm{P}=\mathrm{O}, \mathrm{O}-\mathrm{C}$ in $\mathrm{P}-\mathrm{O}-\mathrm{C}$ and $\mathrm{OH}$ in $\mathrm{P}-\mathrm{OH}$ with an agreement of about $50 \%$ in the library of Nicolet vapour-phase. The phosphorous compound was predicted as an ethylphosphate structure. On the basis of these observations, we proposed a mechanism for the thermal degradation of the organophosphorous alkoxysilane precursor in Fig. 11 similar to Gaan and Sun's work [34]. Under thermal conditions, the polar atom of $\mathrm{P}=\mathrm{O}$ bond could abstract the $\beta$-hydrogen and form a five member cyclic intermediate which could rearrange and form diethylphosphite and vinyltriethoxysilane, this reaction is known as Cope syn elimination. Reverse Michael addition requires acidic conditions that can be initiated by the acidic character of the phosphorus atom of SiP or by the decomposition of SiP precursor into the intermediate diethylphosphite. This product could be easily oxidized into diethylphosphate and could further undergo complex reactions.

3.2.2.2. Fire behaviour: ignition delay. Lyon [35] explains that for a constant ignition temperature, unsteady heat transfer gives the time to ignition (TTI), for a thermally thick sample at a constant external heat flux $\left(\dot{q}_{\text {ext }}^{\prime \prime}\right)$. 


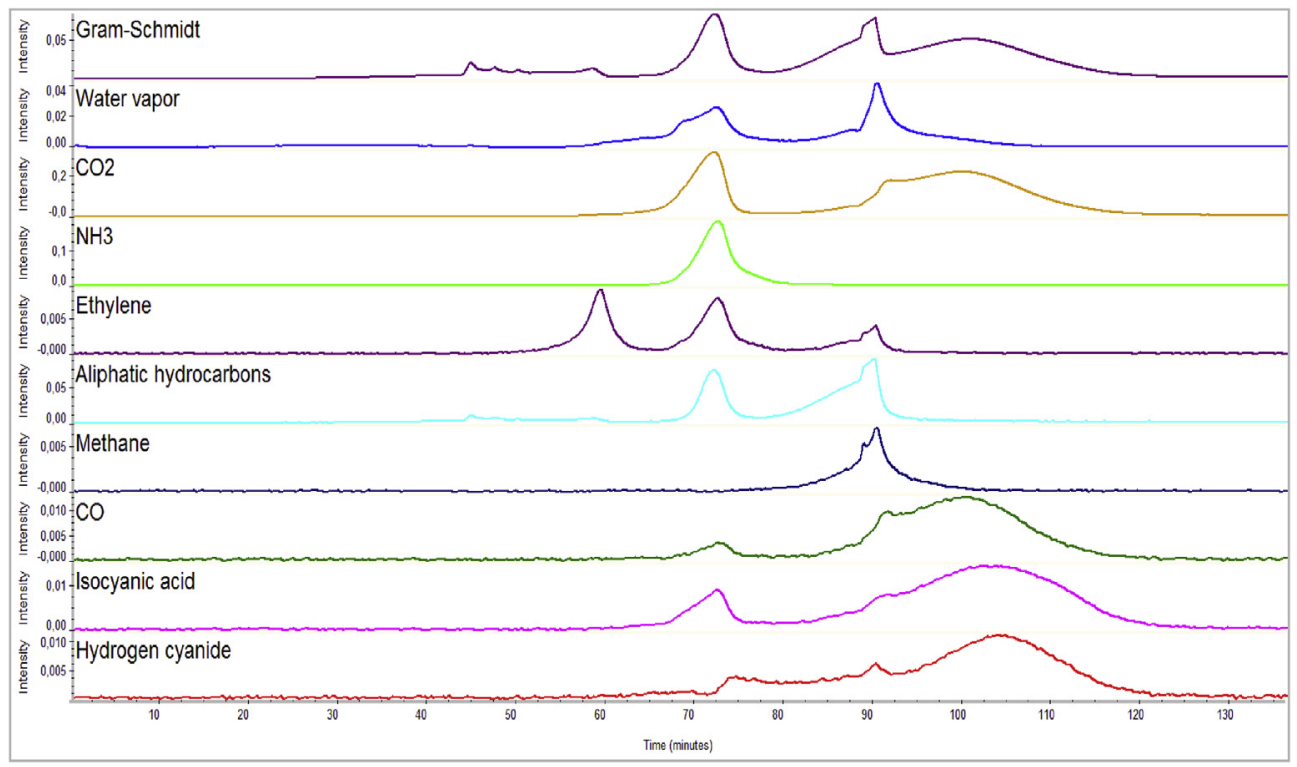

Fig. 7. Gram-Schmidt and chemigrams of C13SiP under air.

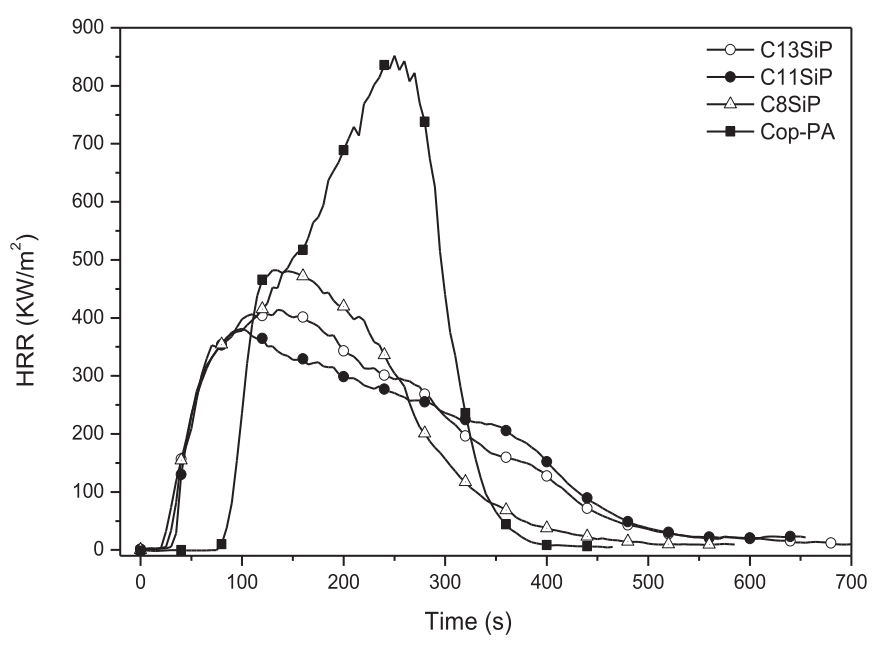

Fig. 8. HRR curves for pure Cop-PA and Cop/SiP nanocomposites versus time at $50 \mathrm{~kW} /$ $\mathrm{m}^{2}$.

$\frac{1}{\sqrt{\text { TTI }}}=\frac{\dot{q}_{\text {ext }}^{\prime \prime}-\dot{q}_{\text {critical }}^{\prime \prime}}{\text { TRP }}=\frac{\dot{q}_{\text {ext }}^{\prime \prime}-\dot{q}_{\text {critical }}^{\prime \prime}}{(\sqrt{\pi k \rho c / 2})\left(T_{\text {ign }}-T_{0}\right)}$

In equation (1) TRP is the thermal response parameter, $k, c$ and $\rho$ are respectively the thermal conductivity, the heat capacity and density, $T_{\text {ign }}$ and $T_{0}$ are respectively the ignition and ambient temperature, $\dot{q}_{\text {critical }}^{\prime \prime}$ is the minimum value of external heat flux causing ignition. The plot of the reciprocal square root of the time to

Table 3

Combustion parameters from the cone calorimeter.

\begin{tabular}{llllll}
\hline Sample & TTI $(\mathrm{s})$ & $\begin{array}{l}\text { PHRR } \\
\left(\mathrm{kW} / \mathrm{m}^{2}\right)\end{array}$ & $\begin{array}{l}\text { THR } \\
\left(\mathrm{MJ} / \mathrm{m}^{2}\right)\end{array}$ & $\begin{array}{l}\text { EHC } \\
(\mathrm{kJ} / \mathrm{g})\end{array}$ & $\begin{array}{l}\text { Residue } \\
(\mathrm{wt} \%)\end{array}$ \\
\hline Cop-PA & 77 & 886 & 140.1 & 29.57 & 0.63 \\
Cop-8SiP & 43 & 540 & 119.1 & 26.72 & 4.29 \\
Cop-11SiP & 34 & 385 & 111.5 & 25.80 & 8.17 \\
Cop-13SiP & 30 & 410 & 115.8 & 25.86 & 7.29 \\
\hline
\end{tabular}

ignition versus the external heat flux has a slope proportional to the reciprocal average value of the thermal response parameter $2^{(\pi k p c)-}$ $1 / 2 . k \rho c$ is called the thermal inertia. Extrapolation of the line with the $x$-axis gives the critical heat flux $\left(\dot{q}_{\text {critical }}^{\prime \prime}\right)$. Considering the measurement uncertainties, Fig. 12 shows a critical heat flux of about $15 \mathrm{~kW} / \mathrm{m}^{2}$ for Cop-PA close to the one found in the literature for the PA66 (15-20 kW/m²) [36] and $0.8 \mathrm{~kW} / \mathrm{m}^{2}$ for C11SiP based composite.

We can conclude that the nanocomposites have an ability to be ignited earlier than the copolymer according to the very low critical values of ignitability.

\subsubsection{HRR curves and barrier effect study}

Fig. 8 also shows that HRR curves are modified from the neat Cop-PA to SiP based nanocomposites, indicating that the fire behaviour of the polyamide has been changed. In the case of CopPA, HRR increases continuously and the pHRR is reached just before the end of the test when fuel depletion occurs. In the case of SiP containing materials, PHRR is reached just after the ignition and then HRR slowly decreases revealing a controlled release of fuel that could be assigned to the formation of protective residue at the sample surface.

Based on the classification of Schartel and Hull [37], these observations allow us to conclude that the burning behaviour of the copolymer is characteristic of an "intermediate thick non-charring material", while C11SiP and C13SiP are a "thermally thick charring samples" or residue forming materials. As the char layer thickens with time, the value of HRR decreases until the extinction of the sample. Residues images are shown in Fig. 13.

According to residues pictures, it was inferred that the Cop-PA (a) forms a few residue after the cone calorimeter test. However, with the incorporation of $8 \mathrm{wt} \%$ of $\mathrm{SiP}$ (b), the appearance of a thin charred layer was observed, but not enough cohesive to cover the entire surface of the sample. This is likely due to the very small percentage of phosphorus $(0.74 \mathrm{wt} \% \mathrm{P})$. By contrast, with the C11SiP and $\mathrm{C} 13 \mathrm{SiP}$ residues (c, d), the formation of a compact and well expanded charred layer was highlighted, covering the entire surface of the material and acting as a protective barrier effect. Hence this behaviour is characteristic of charring materials. 


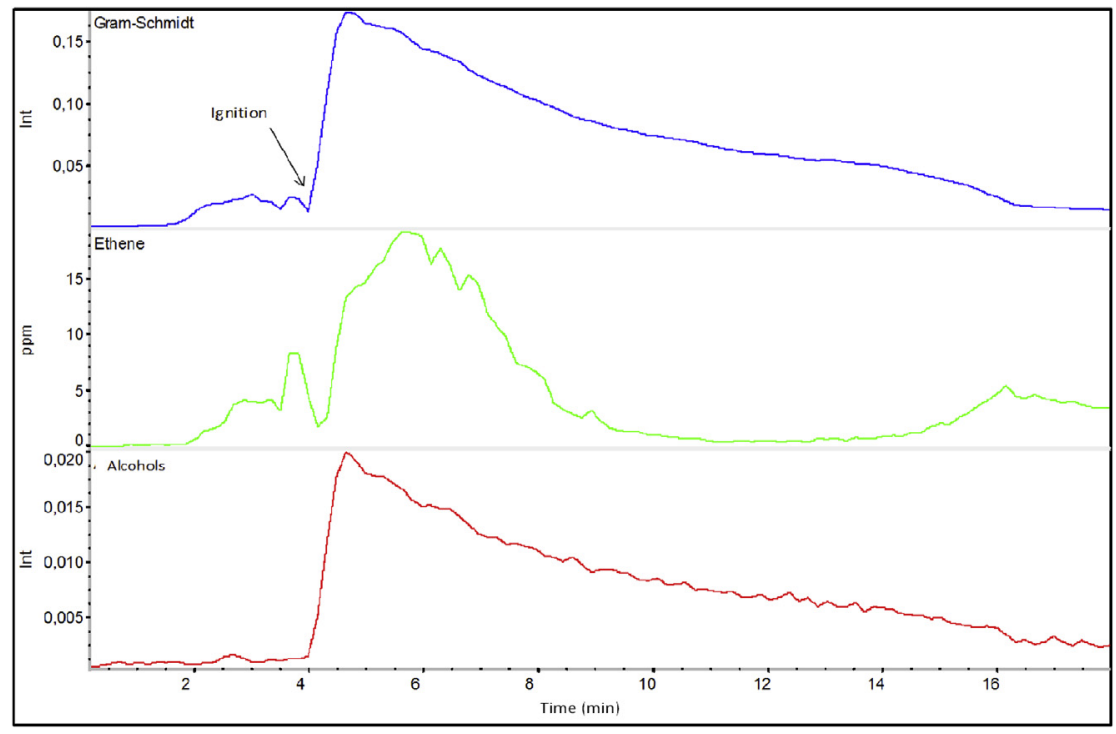

Fig. 9. Gram-Schmidt and chemigrams of some quantified gases in IR for C11SiP.

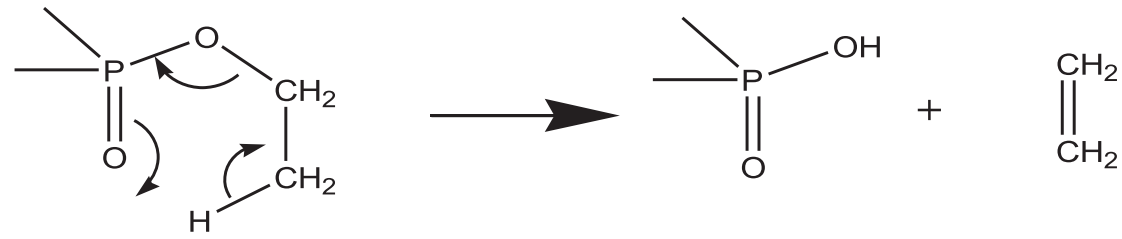

Fig. 10. Formation of ethylene by McLafferty rearrangement [32].

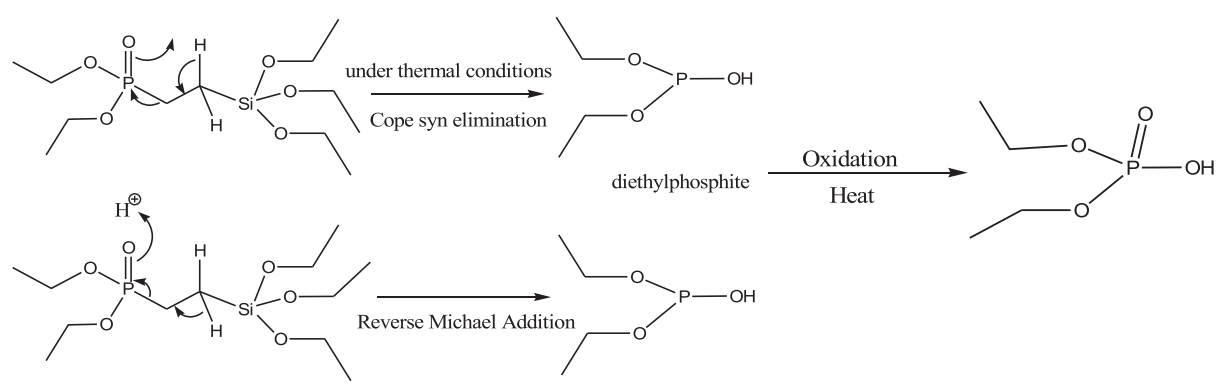

Fig. 11. Proposed mechanism of thermal decomposition of SiP precursor.
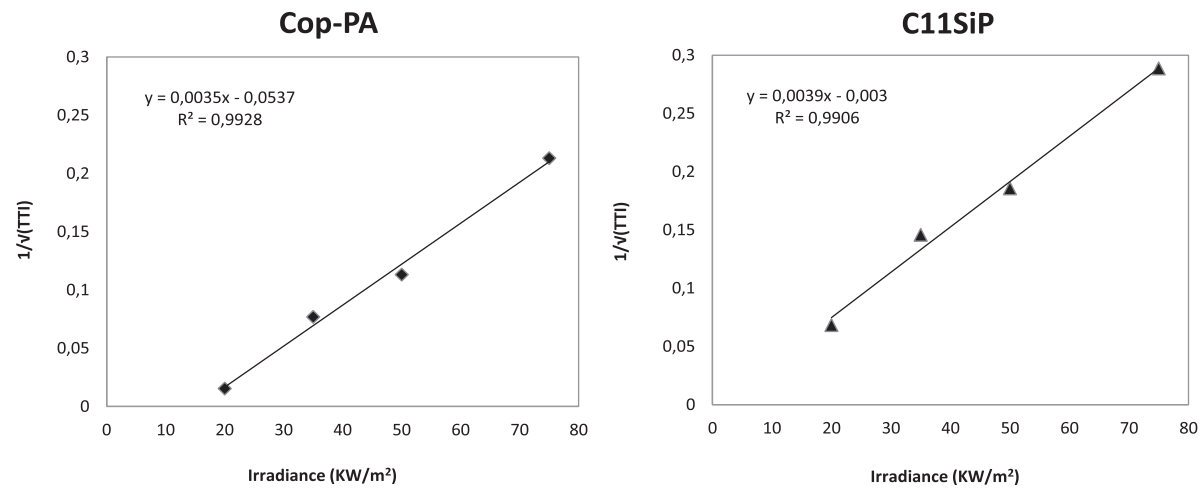

Fig. 12. $1 / \sqrt{\mathrm{TTI}}=f($ external heat flux $)$ for Cop-PA and C11SiP. 

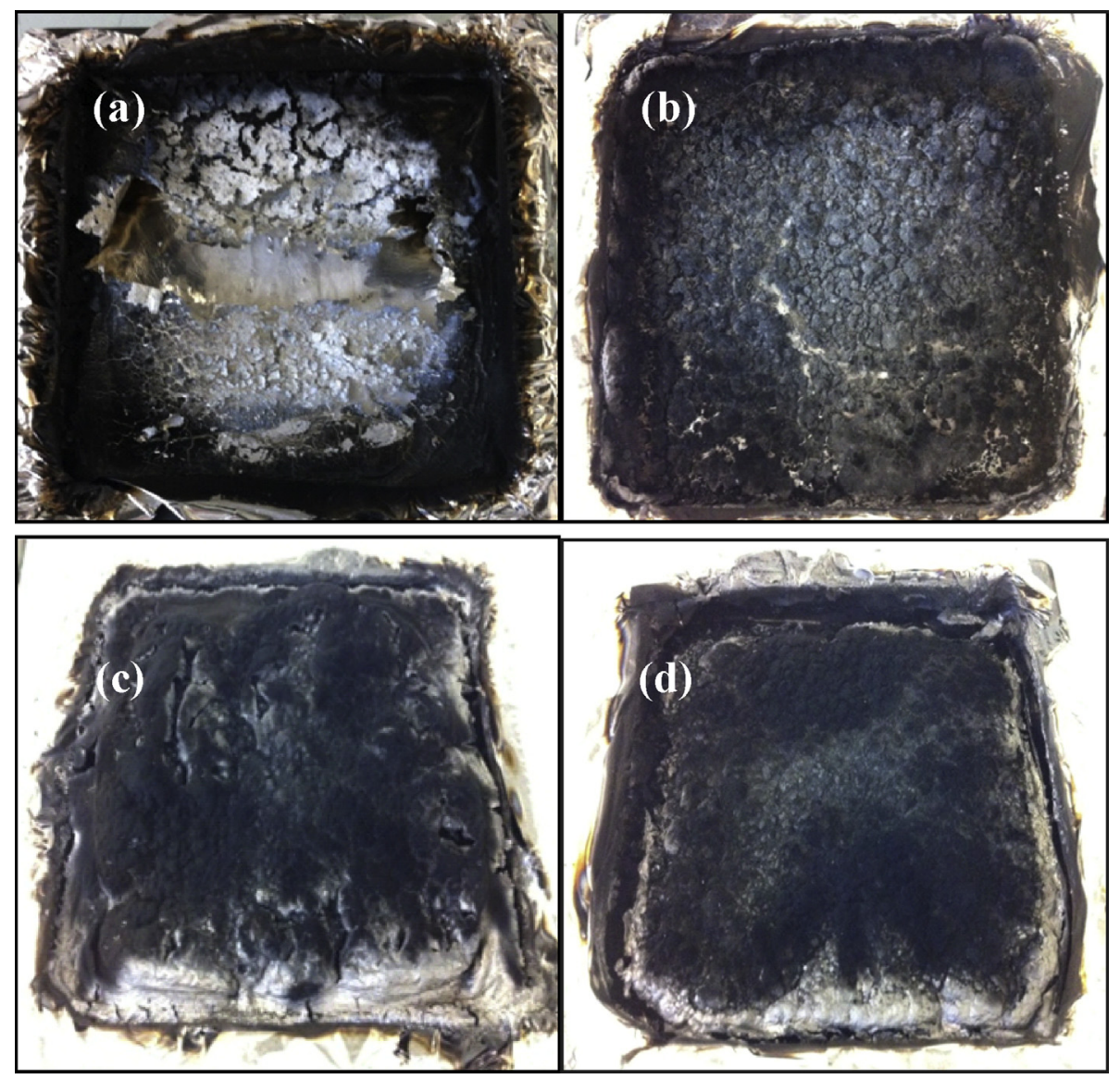

Fig. 13. Pictures of the residues obtained in the cone calorimeter of Cop-PA (a), C8SiP (b), C11SiP (c) and C13SiP (d).

In order to show that the charred layer formed on the surface of the material is well compact, a microstructural analysis of C11SiP residue by SEM was conducted.

3.2.3.1. Residue morphology. The morphology of the residue C11SiP is shown in Fig. 14. The charred layer presents an expanded and cohesive structure. At larger magnification, the residue consists of small white spherical elementary agglomerated particles, thereby forming a dense, homogeneous network, hence the cohesion (left image) of the barrier layer that we obtained in the cone calorimeter test.
3.2.3.2. Condensed phase study/barrier effect. The use of temperature measurements within burning polymer sample was investigated by Schartel and Weiss [38] to obtain deeper information on the actual pyrolysis conditions and flame retardancy mechanism. On this basis, the temperature profiles of the exposed upper surfaces of specimens were measured during the cone calorimeter test. For this purpose, the distance between the cone heater and the sample was changed from 25 to $60 \mathrm{~mm}$ to allow a correct measurement with the same external heat flux of $50 \mathrm{~kW} / \mathrm{m}^{2}$. An infrared camera (Optris) was placed in an inclined position above the specimen in order to record the temperatures field of the upper
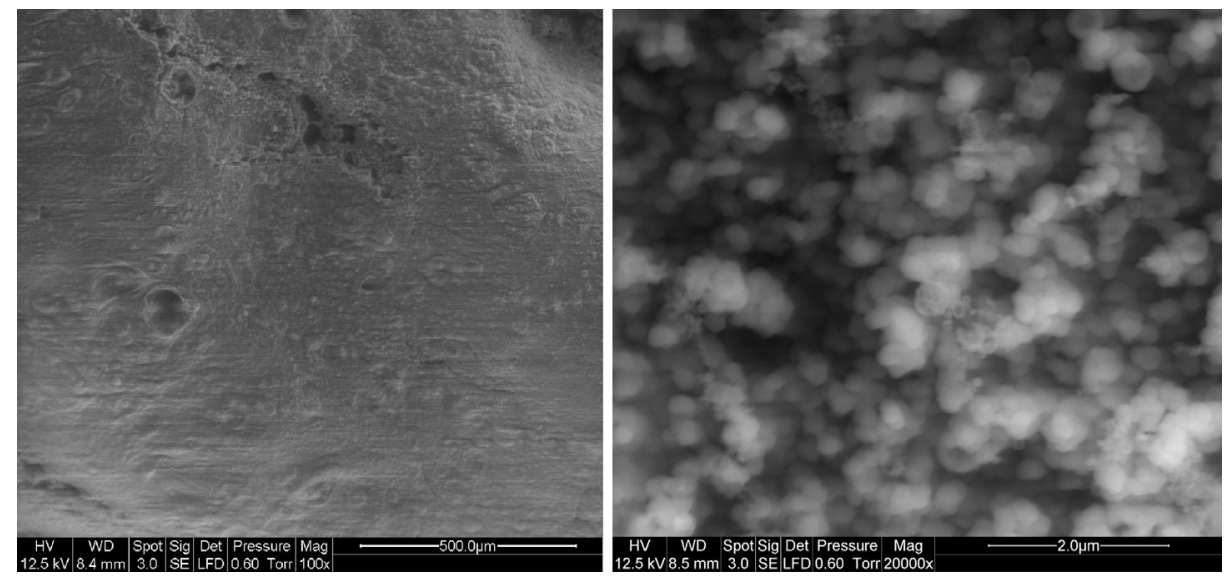

Fig. 14. SEM photographs of the residue C11SiP. 
surface of the sample. The inclination of the infrared camera was of few degrees relative to the perpendicular position, which limits the error on measurements [39]. The infrared camera is calibrated to measure temperatures in the range $125-900{ }^{\circ} \mathrm{C}$.

The external heat flux $\left(\dot{q}_{\text {ext }}^{\prime \prime}\right)$ heats the sample so that the surface temperature increases with time, hence the heat flux reradiated from the surface $\left(\dot{q}_{\text {rerad }}^{\prime \prime}\right)$ increases and the heat flux remaining to heat the sample decreases with time. The reradiation of a hot surface is given in the following Equation (2):

$\dot{q}_{\text {rerad }}^{\prime \prime}=\sigma \varepsilon T_{\mathrm{S}}^{4}$

$\sigma=$ Stefan-Boltzmann constant $\left(\mathrm{W} / \mathrm{m}^{2} \mathrm{~K}\right), \quad \varepsilon=$ emissivity, $T_{\mathrm{S}}=$ surface temperature $(\mathrm{K})$.

The pyrolysis behaviour of solid materials can be divided into two types: non-charring and charring. For non-charring materials the surface temperature is supposed to be close to the pyrolysis temperature as a pyrolysis zone moves through the sample. Charring and residue-forming materials exhibit developing rather than quasi-stationary conditions, such as developing temperatures gradients in the condensed phase [38,40]. Fig. 15 shows the temperature profiles as a function of time during the burning of the copolymer and the composite C11SiP respectively. A much faster heating is observed for SiP composite beyond $300{ }^{\circ} \mathrm{C}$ with a lower ignition temperature around $385{ }^{\circ} \mathrm{C}$ against $496{ }^{\circ} \mathrm{C}$ for Cop-PA. For Cop-PA, the temperature after ignition stabilizes around $595-600{ }^{\circ} \mathrm{C}$ and increases at the very end $\left(610^{\circ} \mathrm{C}\right)$ leading to a little black residue of polyamide. On the contrary, for the C11SiP, the formed residue is inert and can be heated at much higher temperatures (around $750-770{ }^{\circ} \mathrm{C}$ ).

Using the measured temperatures of $770{ }^{\circ} \mathrm{C}$ for $\mathrm{C} 11 \mathrm{SiP}$ and $600^{\circ} \mathrm{C}$ as surface temperatures for Cop-PA, the reradiation from the hot surface of C11SiP is increased by a factor of around 2. Considering the same value of $\varepsilon=0.9$ for the Cop-PA [41] and C11SiP, the heat reradiated for Cop-PA is around $29-30$ versus $60 \mathrm{~kW} / \mathrm{m}^{2}$ for C11SiP. A higher fraction of the absorbed heat can then be reradiated from the sample; this mechanism is well known as shielding effect.

\subsubsection{Effective heat of combustion and combustion efficiency}

Elemental analysis of C11SiP residue obtained from the cone calorimeter test is shown in Table 4. As the results show, for similar introduced quantities of silicon and phosphorus (ratio $\mathrm{P} / \mathrm{Si}=1.05$ ), $\mathrm{Si}$ content is three times higher than $\mathrm{P}$ content in the residue (ratio $=0.37$ ). This leads us to conclude that phosphorus in SiP is

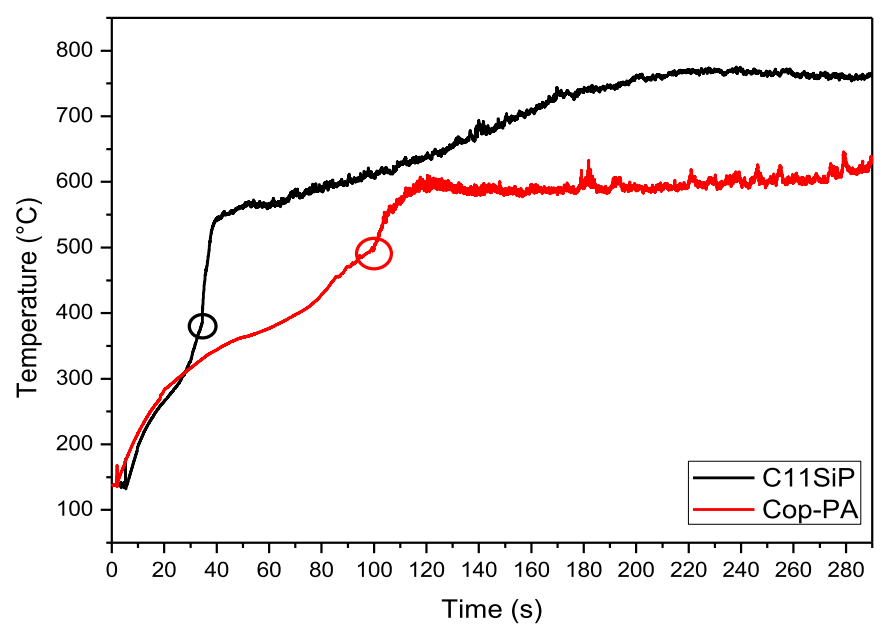

Fig. 15. Temperature profiles of the exposed upper surface for Cop-PA and C11SiP.
Table 4

Data from elemental analysis for samples before and after cone calorimeter test

\begin{tabular}{lllllll}
\hline Sample & $\begin{array}{l}\mathrm{P} / \mathrm{Si} \\
\text { sample }\end{array}$ & $\begin{array}{l}\mathrm{P} / \mathrm{Si} \\
\text { residue }\end{array}$ & $\begin{array}{l}\text { Calculated } \\
\% \text { of } \mathrm{C}^{\mathrm{a}}\end{array}$ & $\begin{array}{l}\text { Calculated } \\
\% \text { of } \mathrm{Si}^{\mathrm{a}}\end{array}$ & $\begin{array}{l}\text { Calculated } \\
\% \text { of } \mathrm{P}^{\mathrm{a}}\end{array}$ & $\begin{array}{l}\text { Residue } \\
(\text { wt\% })\end{array}$ \\
\hline C11SiP & 1.05 & 0.37 & 2.34 & 1.61 & 0.60 & 8.39 \\
\hline
\end{tabular}

a Elemental wt\% based on the weight of the residue in the cone calorimeter test

partially evolved as decomposition gases during combustion with a possible flame retardant action in the vapour phase. Moreover it can be concluded that SiP produces a double effect in the condensed phase: on one side phosphorus promotes charring and on the other side silicon participates to the formation of a stable and cohesive residue.

With the aim to determine the action of SiP in the vapour phase, effective heat of combustion (EHC) has been calculated. The release of phosphorous species may affect EHC by three ways: (i) it could reduce the combustion efficiency $(\chi)$ due to flame inhibition effect, (ii) their complete combustion may release less heat than that of polymer degradation products, (iii) the char promoted by phosphorus "stores" carbon and then energy. If the "potential" EHC of this char (released when oxidized) is high (>EHC of Cop-PA), the EHC of C11SiP decreases. According to the low amount of phosphorus, the way (ii) is highly unlikely.

In order to understand if the phosphorous compounds released into the gas phase have an influence as flame inhibitor, the combustion efficiency $(\chi)$ [42] was calculated from the equation below (3):

$\chi=\frac{\mathrm{EHC}_{\mathrm{CC}}}{\mathrm{EHC}_{\mathrm{PCFC}}}=\frac{\mathrm{EHC}_{\mathrm{CC}}}{\mathrm{THR}_{\mathrm{PCFC}} / \mathrm{ML}_{\mathrm{TGA}}}$

where $\mathrm{EHC}_{\mathrm{CC}}=$ effective heat of combustion from the cone calorimeter, $\mathrm{EHC}_{\mathrm{PCFC}}=$ effective heat of combustion calculated from $\mathrm{THR}_{\mathrm{PCFC}}=$ total heat release from the pyrolysis combustion flow calorimeter, and $\mathrm{ML}_{\mathrm{TGA}}=$ mass loss from the TGA under He.

From the results shown in Table 5, the combustion efficiency value in the cone calorimeter is close to 1 , which means that the combustion is almost complete. This proves that the decrease in EHC values is not due to flame inhibition effect but more probably to the formation of a char which "stores" a high amount of energy. On the whole, the presence of SiP does not strongly affect the gas phase during combustion.

\subsubsection{Total heat release}

Table 3 outlines that THR values for SiP based nanocomposites are lower than that of pure Cop-PA of about 13-19\%. Considering the measurement uncertainties, no significant influence was observed between 0.96 and 1.25 wt\% of $\mathrm{P}$ in C11SiP and C13SiP respectively. Finally, according to EHC values and $\chi$ calculation, this decrease in THR values is due to the higher amount of residues in $\mathrm{SiP}$ based materials and to the decrease in EHC values.

\section{Conclusion}

The presence of the organophosphorous silica filler (SiP) generated in situ the molten copolymer through hydrolysis-condensation reaction results in a decrease of the

Table 5

Combustion efficiency data.

\begin{tabular}{llllll}
\hline Sample & THR $_{\text {PCFC }}(\mathrm{kJ} / \mathrm{g})$ & $\mathrm{ML}_{\mathrm{TGA}}$ & $\mathrm{EHC}_{\mathrm{PCFC}}(\mathrm{kJ} / \mathrm{g})$ & $\mathrm{EHC}_{\mathrm{CC}}(\mathrm{MJ} / \mathrm{kg})$ & $\chi$ \\
\hline Cop-PA & 26.9 & 0.98 & 27.48 & 29.28 & 1.06 \\
C11SiP & 25 & 0.93 & 26.79 & 25.86 & 0.96 \\
\hline
\end{tabular}


decomposition temperature $\left(60{ }^{\circ} \mathrm{C}\right.$ for $\mathrm{C} 11 \mathrm{SiP}$ lower than the neat Cop-PA). This effect is attributed to the release of ethanol and ethylene and also to the decomposition of phosphorus compounds to phosphoric acid which catalyzes the decomposition of the polymer. DTG curves showed also that the degradation of the SiP based nanocomposites takes place in two steps. Major degradation products under air and helium were identified, thus showing that the addition of the SiP does not disturb the mechanism of degradation pathway of the copolymer.

The fire properties measured with a cone calorimeter showed a faster ignition of the SiP based composite. This is due to the presence of ethanol and ethylene before ignition, these gases can cause ignition. Ethylene is a highly flammable gas, its emission was monitored. Hence, we have shown that the release of this gas is due on one hand to the dehydration of ethanol at high temperatures and on the other hand to the rearrangement of the phosphorus compound. The results of fire tests also showed a reduction of about $57 \%$ of the peak HRR with the addition of only 0.91 wt\% of Si and 0.96 wt\% of P. Moreover we observed that the phosphorus compounds upon degradation, release polyphosphoric acids that promote charring of the material. Therefore, HRR curves were modified for all materials, evidencing that the burning behaviour of the polyamide has been changed. These observations allowed us to conclude that the copolymer is characteristic of an "intermediate thick non charring material" while the mixtures C11SiP and C13SiP are characteristic of "Thermally thick charring materials." Finally, the elemental analysis of the residue, the combustion efficiency and the measured temperatures of the exposed upper surface during the cone calorimeter test allowed us to deduce that on one side phosphorus promotes carbonization, and on the other side silicon improves stability, both act in the condensed phase according to a mechanism called "heat shielding effect".

Our next purpose will be to study a new type of Si-P systems, by substituting the structure of the phosphorus group of SiP in order to overcome the only problem, which is the early ignition of the SiP based nanocomposites [43].

\section{References}

[1] Lomakin SM, Zaikov GE, Artsis MI. Advances in nylon 6,6 flame retardancy. Int J Polym Mater 1996;32:173-202.

[2] van der Veen I, de Boer J. Phosphorus flame retardants: properties, production, environmental occurrence, toxicity and analysis. Chemosphere 2012;88: 1119-53.

[3] Levchik SV, Weil ED. Combustion and fire retardancy of aliphatic nylons Polym Int 2000:49:1033-73.

[4] Laoutid F, Bonnaud L, Alexandre M, Lopez-Cuesta JM, Dubois P. New prospects in flame retardant polymer materials: from fundamentals to nanocomposites. Mater Sci Eng R: Rep 2009;63:100-25.

[5] Braun U, Balabanovich AI, Schartel B, Knoll U, Artner J, Ciesielski M, et al. Influence of the oxidation state of phosphorus on the decomposition and fire behaviour of flame-retarded epoxy resin composites. Polymer 2006;47: 8495-508.

[6] Braun U, Schartel B. Flame retardant mechanisms of red phosphorus and magnesium hydroxide in high impact polystyrene. Macromol Chem Phys 2004;205:2185-96.

[7] Lewin M, Weil ED. Mechanisms and modes of action in flame retardancy of polymers. In: Horrocks AR, Price D, editors. Fire retardant materials. Woodhead Publishing; 2001. p. 31-68 [chapter 2].

[8] Davis J. The technology of halogen-free flame retardant additives for polymeric systems. Eng Plast 1996:9:403-19.

[9] Schartel B, Kunze R, Neubert D. Red phosphorus-control led decomposition for fire retardant PA 66. J Appl Polym Sci 2002;83:2060-71.

[10] Levchik SV, Costa L, Camino G. Effect of the fire-retardant ammonium polyphosphate on the thermal-decomposition of aliphatic polyamides. 3. Polyamides 6.6 and 6.10. Polym Degrad Stab 1994;43:43-54.

[11] Levchik SV, Costa L, Camino G. Effect of the fire-retardant, ammonium polyphosphate, on the thermal decomposition of aliphatic polyamides: part II-polyamide 6. Polym Degrad Stab 1992;36:229-37.
[12] Fu XM, Liu Y, Wang Q Zhang ZJ, Wang ZY, Zhang JZ. Novel synthesis method for melamine polyphosphate and its flame retardancy on glass fiber reinforced polyamide 66. Polym-Plast Technol Eng 2011:50: $1527-32$.

[13] Jahromi S, Gabrielse W, Braam A. Effect of melamine polyphosphate on thermal degradation of polyamides: a combined X-ray diffraction and solidstate NMR study. Polymer 2003;44:25-37.

[14] Seefeldt H, Duemichen E, Braun U. Flame retardancy of glass fiber reinforced high temperature polyamide by use of aluminum diethylphosphinate: thermal and thermo-oxidative effects. Polym Int 2013;62: $1608-16$.

[15] Braun U, Bahr H, Schartel B. Fire retardancy effect of aluminium phosphinate and melamine polyphosphate in glass fibre reinforced polyamide 6. e-Polymers 2010;10(1):443-56.

[16] Braun U, Schartel B. Flame retardancy mechanisms of aluminium phosphinate in combination with melamine cyanurate in glass-fibrereinforced poly(1,4-butylene terephthalate). Macromol Mater Eng 2008;293:206-17.

[17] Braun U, Bahr H, Sturm H, Schartel B. Flame retardancy mechanisms of metal phosphinates and metal phosphinates in combination with melamine cyanurate in glass-fiber reinforced poly(1,4-butylene terephthalate): the influence of metal cation. Polym Adv Technol 2008;19: $680-92$.

[18] Braun U, Schartel B, Fichera MA, Jager C. Flame retardancy mechanisms of aluminium phosphinate in combination with melamine polyphosphate and zinc borate in glass-fibre reinforced polyamide 6,6. Polym Degrad Stab 2007:92:1528-45.

[19] Naik AD, Fontaine G, Samyn F, Delva X, Bourgeois Y, Bourbigot S. Melamine integrated metal phosphates as non-halogenated flame retardants: synergism with aluminium phosphinate for flame retardancy in glass fiber reinforced polyamide 66. Polym Degrad Stab 2013;98: 2653-62.

[20] Bahloul W, Melis F, Bounor-Legare V, Cassagnau P. Structural characterisation and antibacterial activity of $\mathrm{PP} / \mathrm{TiO}_{2}$ nanocomposites prepared by an in situ sol-gel method. Mater Chem Phys 2012;134:399-406.

[21] Bahloul W, Oddes O, Bounor-Legare V, Melis F, Cassagnau P, Vergnes B. Reactive extrusion processing of Polypropylene/TiO2 nanocomposites by in situ synthesis of the nanofillers: experiments and modeling. AIChE J 2011;57: 2174-84.

[22] Van Nieuwenhuyse P, Bounor-Legare V, Boisson F, Cassagnau P, Michel A. Hydrolysis-condensation reactions of diethylphosphato-ethyltriethoxysilane with tetraethoxysilane studied by Si-29-NMR: solvent and phosphonate catalytic effect. J Non-Crystal Solids 2008;354:1654-63.

[23] Theil-Van Nieuwenhuyse R, Bounor-Legare V, Bardollet P, Cassagnau P, Michel A, David L, et al. Phosphorylated silica/polyamide 6 nanocomposites synthesis by in situ sol-gel method in molten conditions: Impact on the fireretardancy. Polym Degrad Stab 2013;98:2635-44.

[24] Liquori AM, Mele A. Viscous behavior of polyhexamethylenadipamide molecules in solution. J Polym Sci 1954;13:589-94.

[25] Aliev A, Ou DL, Ormsby B, Sullivan AC. Porous silica and polysilsesquioxane with covalently linked phosphonates and phosphonic acids. J Mater Chem 2000; $10: 2758-64$

[26] Huggett C. Estimation of rate of heat release by means of oxygenconsumption measurements. Fire Mater 1980;4:61-5.

[27] Dabrowski F, Bourbigot S, Delobel R, Le Bras M. Kinetic modelling of the thermal degradation: of polyamide-6 nanocomposite. Eur Polym J 2000;36: $273-84$.

[28] Braun E, Levin BC. Nylons - a review of the literature on products of combustion and toxicity. Fire Mater 1987:11:71-88.

[29] Hornsby PR, Wang J, Rothon R, Jackson G, Wilkinson G, Cossick K. Thermal decomposition behaviour of polyamide fire-retardant compositions containing magnesium hydroxide filler. Polym Degrad Stab 1996;51: $235-49$.

[30] Levchik SV, Weil ED, Lewin M. Thermal decomposition of aliphatic nylons. Polym Int 1999;48:532-57.

[31] Walters RN, Hackett SM, Lyon RE. Heats of combustion of high temperature polymers. Fire Mater 2000;24:245-52.

[32] Canadell J, Hunt BJ, Cook AG, Mantecon A, Cadiz V. Phosphorylated copolymers containing pendant, crosslinkable spiro orthoester moieties. J Polym Sci Pol Chem 2006;44:6728-37.

[33] Gentilhomme A, Cochez M, Ferriol M, Oget N, Mieloszynski JL. Thermal degradation of methyl methacrylate polymers functionalized by phosphoruscontaining molecules - II: initial flame retardance and mechanistic studies. Polym Degrad Stab 2003;82:347-55.

[34] Gaan S, Sun G. Effect of phosphorus and nitrogen on flame retardant cellulose: a study of phosphorus compounds. J Anal Appl Pyrolysis 2007;78: $371-7$.

[35] Richard E, Lyon MLJ. Polymer flammability. 2005.

[36] Lyon RE, Quintiere JG. Criteria for piloted ignition of combustible solids. Combust Flame 2007:151:551-9.

[37] Schartel B, Hull TR. Development of fire-retarded materials - interpretation of cone calorimeter data. Fire Mater 2007;31:327-54.

[38] Schartel B, Weiss A. Temperature inside burning polymer specimens: pyrolysis zone and shielding. Fire Mater 2010;34:217-35. 
[39] Sonnier R, Caro-Bretelle AS, Dumazert L, Longerey M, Otazaghine B. Influence of radiation-crosslinking on flame retarded polymer materials - how crosslinking disrupts the barrier effect. Radiat Phys Chem 2015;106: $278-88$.

[40] Quintiere JG. Fire growth: an overview. Fire Technol 1997;33:7-31.

[41] Linteris GT, Lyon RE, Stoliarov SI. Prediction of the gasification rate of thermoplastic polymers in fire-like environments. Fire Saf J 2013;60:14-24.
[42] Sonnier R, Otazaghine B, Ferry L, Lopez-Cuesta J-M. Study of the combustion efficiency of polymers using a pyrolysis-combustion flow calorimeter. Combust Flame 2013;160:2182-93.

[43] Sahyoun J, Bounor-Legaré V, Ferry L, Sonnier R, Da Cruz-Boisson F, Mélis F, et al. Synthesis of a new organophosphorous alkoxysilane precursor and its effect on the thermal and fire behaviour of a PA66/PA6 copolymer. Eur Polym J. http://dx.doi.org/10.1016/j.eurpolymj.2015.02.036. 